\title{
Competências para a sustentabilidade organizacional: a proposição de um framework representativo do acontecimento da ecoeficiência
}

\author{
Luciano Munck $^{\mathrm{a} *}$, Bárbara Galleli ${ }^{\mathrm{b}}$, Rafael Borim de Souza ${ }^{\mathrm{c}}$ \\ a*munck@uel.br, UEL, Brasil \\ bb.gallelidias@gmail.com, UEL, Brasil \\ crafaborim@yahoo.com, UFPR, Brasil
}

\begin{abstract}
Resumo
0 fato de as organizações conseguirem estruturar suas competências em um modelo de gestão específico é apenas ponto inicial para o desenvolvimento de um planejamento estratégico vinculado aos aspectos da sustentabilidade. Por meio dos elementos constitutivos da ecoeficiência (propostos pelo World Business Council for Sustainable Development), os quais são tratados neste artigo como competências organizacionais, desenvolveu-se a presente pesquisa por uma perspectiva essencialmente teórica, com o objetivo de propor um framework representativo do acontecimento da ecoeficiência organizacional via competência que indique o potencial de ser ecoeficiente das organizações, a partir da avaliação de entregas de suas competências.
\end{abstract}

Palavras-chave

Ecoeficiência. Sustentabilidade. Competência organizacional.

\section{Introdução}

0 desenvolvimento sustentável mostra-se um fenômeno multidisciplinar (MEBRATU, 1998). Tal característica faz necessária a observação de inúmeras ciências, tal como as ciências sociais aplicadas, dentre as quais, para o escopo de análise deste artigo, prioriza-se a administração. 0 desenvolvimento sustentável importa para a administração nos meios pelos quais as organizações expressam um engajamento com causas sustentáveis (GLADWIN; KENNELLY; KRAUSE, 1995).

Esse engajamento será denominado ao longo deste estudo teórico como sustentabilidade organizacional que, em síntese, agrega à gestão das organizações a responsabilidade de inserir preocupações relacionadas ao desenvolvimento sustentável em decisões estratégicas (VAN MARREWIJK, 2003).

A ideia da ecoeficiência é inerente às discussões de sustentabilidade organizacional (SAVITZ; WEBER,
2007). Quando a organização busca por métodos de redução dos impactos negativos gerados por suas atividades e de utilização mais responsável dos recursos produtivos consumidos por ela, admite-se que existe um interesse de conquistar um estágio maior de eficiência, no caso, de ecoeficiência (BLEISCHWITZ, 2003).

Para que possa ser gerenciada, a ecoeficiência, parte integrante da sustentabilidade organizacional, depende de um mecanismo de gestão que conceda a ela a capacidade de ser avaliada, mensurada e, principalmente, aprimorada (KAPTEIN; WEMPE, 2002). Dentre as ferramentas gerenciais valorizadas pela administração contemporânea destacam-se as competências organizacionais, as quais constituem atos corporativos moldados e configurados pela presença e interação dos recursos, dos indivíduos e das tecnologias presentes nas organizações (DREJER, 2002; MAGGl, 2006; MILLS et al., 2002). 
Por esse contexto de discussão, desenvolveu-se o presente artigo com o objetivo de propor um framework representativo do acontecimento da ecoeficiência organizacional via competência, ou seja, um framework que, por meio da verificação do nível de entrega das competências de suporte da ecoeficiência, indique o potencial de a organização ser ecoeficiente, em palavras mais diretas, o potencial de desenvolvimento da competência foco da ecoeficiência. 0 objetivo de propor um framework ganha relevância à medida que os frameworks são utilizados como forma de traduzir temas complexos, possibilitando que esses sejam estudados e analisados (SHEHABUDDEEN; PROBERT; PHAAL, 2000).

Em pesquisas realizadas nos periódicos qualificados pela Capes no ano de 2009 como A1 e A2 nas áreas de administração, ciências contábeis e turismo, artigos que fizeram menção em seu título à sustentabilidade, ao desenvolvimento sustentável, à ecoeficiência e às competências foram investigados por meio da leitura de seus abstracts. De todos os periódicos assim caracterizados, 59 foram pesquisados desde a data de fundação. Foram encontrados 79 artigos que apresentavam alguma menção à sustentabilidade, ao desenvolvimento sustentável e à ecoeficiência e 59 artigos que possuíam em seu título algum termo aludindo às competências. Não foi encontrado nenhum trabalho que já tenha usufruído do objetivo geral de pesquisa proposto por meio deste artigo.

Além disso, ao se analisarem alguns modelos de gestão da sustentabilidade organizacional, buscou-se por alguma menção, ainda que indireta, a critérios e características que remetessem a considerações sobre competências. Cinco estruturas de compreensão da sustentabilidade organizacional como fenômeno de gestão nas organizações foram tomadas como referência, em inglês: the triple-bottom-line (ELKINGTON, 1999), the theory of corporate integrity (KAPTEIN; WEMPE, 2002), the triple-top-line (McDONOUGH; BRAUNGART, 2002), the four spheres framework for sustainability (O'CONNOR, 2006) e the ecological sustainability trigon (MARQUES et al., 2009). Esses são modelos amplamente discutidos em diversos artigos nacionais e internacionais pela intenção comum de esclarecer como a sustentabilidade pode vir a ser considerada nas análises dos diversos cenários de gestão. Todavia, em nenhuma delas foram constatadas menções que permitissem relacionar, ainda que de maneira mais generalizada, sustentabilidade, ecoeficiência e competências.

Para melhor compreensão do tema em investigação, o presente artigo foi desenvolvido com a apresentação das seguintes seções: introdução; procedimentos metodológicos; considerações sobre a sustentabilidade organizacional; premissas da ecoeficiência; competências organizacionais; a relação entre competências, sustentabilidade organizacional e ecoeficiência; ferramenta de análise de competências viabilizadoras da ecoeficiência; e, considerações finais, sugestões de estudos futuros e implicações para a administração.

\section{Procedimentos metodológicos}

0 presente artigo foi desenvolvido com o objetivo de propor um framework que, por meio da verificação do nível de entrega das competências de suporte da ecoeficiência, indique o potencial de ser ecoeficiente da organização, ou seja, o potencial de desenvolvimento da competência foco da ecoeficiência.

No intuito de responder ao objetivo supramencionado foi realizada uma pesquisa de natureza teórica, buscando responder ao problema com uma abordagem qualitativa cujos objetivos foram analisados por uma perspectiva exploratória e que, em relação aos procedimentos técnicos, é classificada como bibliográfica (RICHARDSON, 2008).

Demo (2000) ressalta que uma pesquisa teórica não exige e, principalmente, não implica uma imediata intervenção na realidade, mas nem por isso deixa de ser importante, pois é por ela que são criadas condições para futuras investigações empíricas.

Trata-se de uma pesquisa qualitativa orientada por uma abordagem objetivista, ou seja, o que se busca é a fundamentação teórico-analítica que facilite, em um momento de intervenção empírica, a aquisição de relatos mais objetivos; nesse sentido compreende-se a realidade como uma estrutura composta por uma rede de relacionamentos determinados entre as partes constituintes da sociedade (MORGAN; SMIRCICH, 1980; DENZIN; LINCOLN, 2006).

A abordagem qualitativa desta pesquisa indica que houve um levantamento teórico sobre os temas de interesse a fim de que, por meio da observação das contribuições acadêmicas contemporâneas a respeito dos assuntos aqui abordados, fosse possivel propor o framework, o qual foi complementado pela apresentação de uma ferramenta de pesquisa que almeja proporcionar maior objetividade em futuras intervenções empíricas.

Gil $(2008$, p. 27) considera que as "[...] pesquisas exploratórias são desenvolvidas com o objetivo de proporcionar uma visão geral, de tipo aproximativo, acerca de determinado fato [...]". A pesquisa se torna exploratória quando o tema escolhido é pouco explorado e apresenta dificuldade elevada para a formulação de hipóteses precisas e operacionalizáveis.

Como foi demonstrado na introdução, pela análise dos artigos publicados nos periódicos classificados 
pela Capes em 2009 como A1 e A2 não foram encontradas pesquisas que já tenham tratado do objetivo proposto neste estudo, o que também ficou comprovado pela análise das estruturas de compreensão da sustentabilidade organizacional. A ausência de pesquisas que tenham vinculado em um mesmo escopo análises sobre competências e ecoeficiência faz com que a tarefa de operacionalização de variáveis e de levantamento de hipóteses científicas se torne mais complexa, bem como exige a realização de uma pesquisa teórica que anteceda futuros trabalhos empíricos sobre o tema. Pela constatação de tal necessidade, reafirma-se a relevância deste artigo.

Por ser teórica, qualitativa e exploratória, coube a este estudo o procedimento técnico do levantamento bibliográfico. De acordo com Martins e Theóphilo (2007), a pesquisa bibliográfica é uma estratégia necessária para a condução de qualquer pesquisa científica, pois procura explicar e discutir um assunto, tema ou problema com base em referências publicadas em livros acadêmicos, periódicos e anais de congressos nacionais e internacionais.

Nesse contexto, foram selecionados os seguintes temas como os mais relevantes para serem discutidos em prol de que o objetivo proposto alcançasse resposta: sustentabilidade organizacional, premissas da ecoeficiência, competência organizacional e a relação entre as competências e a ecoeficiência. 0 Quadro 1 apresenta o que foi investigado em cada um desses temas, bem como indica os principais autores utilizados para a elaboração do referencial teórico que se segue.

\section{Considerações sobre a sustentabilidade organizacional}

Segundo Shwom (2009), as origens sociais de muitos dos problemas ecológicos e as soluções atualmente observadas podem ser apontadas nos processos organizacionais e interorganizacionais. Instituições como o capitalismo e o estado podem representar máquinas fomentadoras da degradação ambiental, assim como as decisões individuais que podem ser impactantes ao meio ambiente, no entanto são as organizações as engrenagens que movem essas máquinas (SHWOM, 2009).

Embora o comportamento organizacional de aderir a movimentos intra e interorganizacionais vinculados ao desenvolvimento sustentável seja merecedor de críticas e análises que intentem averiguar os reais interesses que levam as empresas a participarem dessa mobilidade social, é necessário reconhecer que, apesar dos muitos questionamentos e em meio a inúmeras desconfianças, algo já tem sido feito pelas organizações. Tais ações organizacionais procuram estar imbricadas na respectiva estratégia que rege o comportamento socioeconômico dessas empresas, bem por isso, admoesta-se que, em face do desafio de tornarem-se agentes sociais efetivamente representativos na busca de um desenvolvimento sustentável, as organizações têm aprimorado suas práticas de gestão em caminhos estratégicos que as auxiliam a oferecer respostas a tais demandas (MUNCK; BORIM-DE-SOUZA, 2009).

Ao analisar o desenvolvimento sustentável junto às organizações, Silva e Quelhas (2006) conceituam essa expressão como a busca por um equilíbrio entre o que é socialmente desejável, economicamente viável e ambientalmente sustentável. De acordo com Savitz e Weber (2007), a organização é sustentável quando gera lucro para os acionistas, protege 0 meio ambiente e melhora a vida das pessoas com as quais mantém interações. Dyllick e Hockerts (2002) definem a sustentabilidade organizacional como a capacidade de as organizações alavancarem seu capital econômico, social e ambiental a fim de contribuir para o desenvolvimento sustentável em seu domínio político.

Munck e Borim-de-Souza (2009) argumentam que ações organizacionais sustentáveis são aquelas que causam o menor impacto ambiental possível por meio de atividades operacionais preocupadas em simultaneamente promover um desenvolvimento

Quadro 1. Estrutura de investigação temática e procedimentos de pesquisa

\begin{tabular}{|c|c|c|}
\hline Temas & 0 que investigar? & Principais autores \\
\hline Sustentabilidade organizacional & $\begin{array}{l}\text { Apresentação de conceitos e caracterizações que qualificam a } \\
\text { sustentabilidade das organizações. }\end{array}$ & $\begin{array}{l}\text { Savitz e Weber (2007), Van Bellen (2004), } \\
\text { Krajnc e Glavic (2005), Elkington (1999), } \\
\text { Dyllick e Hockerts (2002) }\end{array}$ \\
\hline Premissas da ecoeficiência & $\begin{array}{l}0 \text { que é e qual a importância da ecoeficiência? Uma exploração } \\
\text { sobre a ecoeficiência junto às organizações. }\end{array}$ & $\begin{array}{l}\text { WBCSD (WORLD..., 2000), Dyllick e } \\
\text { Hockerts (2002), Piotto (2003) }\end{array}$ \\
\hline Competência organizacional & $\begin{array}{l}\text { Aspectos conceituais, caracterizações e classificações com foco } \\
\text { na competência organizacional. }\end{array}$ & $\begin{array}{l}\text { Fleury e Fleury (2008), Mills et al. (2002), } \\
\text { Dutra (2001) }\end{array}$ \\
\hline $\begin{array}{l}\text { Relação entre competências e } \\
\text { ecoeficiência }\end{array}$ & $\begin{array}{l}\text { Bases e importância desse vínculo e quais as competências } \\
\text { potencializadoras da ecoeficiência. }\end{array}$ & $\begin{array}{l}\text { Mills et al. (2002), Fleury e Fleury } \\
\text { (2008), WBCSD (WORLD..., 2000), } \\
\text { Borim-de-Souza (2010) }\end{array}$ \\
\hline
\end{tabular}

Fonte: elaborado pelos autores. 
socioeconômico que propicie a sobrevivência das gerações presente e futuras. Tal desenvolvimento, de acordo com os autores, deve ocorrer de modo totalmente dependente das pessoas inseridas em ambientes sociais e organizacionais, já que por elas são estabelecidas as decisões finais validadoras de todas essas proposições.

Pela consideração de que ao exercer suas atividades as organizações consomem não só recursos financeiros mas também ambientais e sociais, Elkington (1999) propôs o relacionamento entre os três pilares da sustentabilidade (o social, o econômico e o ambiental), conhecidos na literatura como Triple Bottom Line - TBL, o qual traduz uma perspectiva cada vez mais aceita pela sociedade e pelas organizações (DYLLICK; HOCKERTS, 2002; NORMAM; MaCDONALD, 2003; KRAJNC; GLAVIC, 2005; JAMALI, 2006; SAVITZ; WEBER, 2007; MUNCK; BORIM-DE-SOUZA, 2009; CALLADO, 2010). Vale ressaltar, conforme as afirmações de Dyllick e Hockerts (2002), que esses três elementos possuem diferentes propriedades e por isso requerem diferentes abordagens de gestão.

Dyllick e Hockerts (2002), em uma tentativa de aproximação da sustentabilidade com a conjectura organizacional, afirmam que os pesquisadores da área intencionam desvendar como as organizações podem promover a sustentabilidade econômica em simultaneidade com o aumento de sua eficiência social e ambiental. Para que uma organização torne-se realmente sustentável é necessário que haja integração de seus pilares econômico, social e ambiental, os quais compõem a sustentabilidade organizacional. Essa visão tripartite será a base deste trabalho e assegura que tanto o desenvolvimento econômico quanto a qualidade ambiental e a justiça social sejam relevantes para a compreensão da sustentabilidade.

Almejando jogar luz na necessidade de integração dos pilares, bem como dar-lhes mais evidência conceitual e prática, convencionou-se aqui, utilizando como bases os referenciais estudados, converter os pilares da sustentabilidade organizacional em três sustentabilidades: sustentabilidade organizacional econômica, sustentabilidade organizacional ambiental e sustentabilidade organizacional social. As três sustentabilidades tornam-se então sustentadoras e viabilizadoras da sustentabilidade organizacional. Estudos que se utilizam da mesma terminologia (DILLICK; HOCKERTS, 2002; JAMALI, 2006; KRAJNC; GLAVIC, 2005) permitem concluir que os três pilares estão implícitos nas três sustentabilidades organizacionais propostas, contudo, em proporções diferentes. Para alcançar o estado da sustentabilidade, portanto, nessa estrutura conceitual uma organização deve antes desenvolver suas sustentabilidades econômica, ambiental e social de maneira equilibrada e conforme o contexto da organização.

Conforme Lorenzetti, Cruz e Ricioli (2008), sustentabilidade econômica refere-se ao impacto das organizações sobre as condições econômicas das partes interessadas e sobre o sistema econômico em todos os níveis, ou seja, representa a geração de riqueza pela e para a sociedade, por meio do fornecimento de bens e serviços. Segundo Azapagic (2003), a sustentabilidade econômica da organização é peça central do desenvolvimento sustentável, pois, a partir do lucro são providos empregos, por meio dos quais proporciona-se à comunidade a possibilidade de melhores condições de vida. Em uma abordagem mais direta, Dyllick e Hockerts (2002) asseguram que a sustentabilidade econômica de uma organização indica que ela possui a capacidade de realizar suas atividades de maneira responsável com lucratividade considerável.

A sustentabilidade ambiental refere-se à conservação e ao manejo dos recursos naturais. É necessário que a organização, sob a perspectiva dos impactos de suas operações e produtos sobre os sistemas naturais vivos e não vivos, procure minimizar os impactos negativos e amplificar os positivos, tanto em processos de entrada quanto de saída (KRAJNC; GLAVIC, 2005). A responsabilidade sobre o meio natural abrange mais do que o cumprimento da lei ou iniciativas como reciclagem ou uso eficiente de recursos energéticos. Envolve, antes, uma abordagem compreensiva sobre as operações organizacionais (JAMALI, 2006).

A sustentabilidade social, de acordo com Lorenzetti, Cruz e Ricioli (2008), diz respeito ao alcance da igualdade e à participação de todos os grupos sociais na construção e manutenção do equilíbrio do sistema, compartilhando direitos e responsabilidades. Para as organizações, a dimensão social refere-se ao seu impacto no sistema social onde operam; o desempenho social é abordado por meio dessa análise sobre as partes interessadas em nível local, nacional e global. Krajnc e Glavic (2005) afirmam que a sustentabilidade social sob a óptica das organizações refere-se às atitudes organizacionais em relação aos próprios colaboradores, fornecedores, contratados e consumidores, além de impactos na sociedade em geral, para além de seus domínios.

As três sustentabilidades da sustentabilidade organizacional (social, ambiental e econômica) devem confluir de forma articulada para o alcance do desenvolvimento sustentável (CALLADO, 2010). Dessa maneira é possível inferir que uma visão equilibrada a respeito de como fazer uso dos recursos que a natureza oferece é essencial para se garantir às 
gerações futuras uma sociedade de prosperidade e justiça, com melhores qualidades ambiental e de vida.

Esse relacionamento articulado pode ser visto como uma fusão de quesitos a qual ocorre, no início, por uma vinculação estabelecida entre duas variáveis consecutivas: a questão social se alia a preocupações ambientais por meio de atuações socioeconômicas capazes de serem suportadas pela natureza, pela sociedade e pelo sistema econômico; premissas ambientais agregam-se ao pilar econômico por meio de investimentos interessados em promover o crescimento da sociedade por meio de ações viáveis à natureza e à economia; e, o sistema econômico une-se ao social quando análises de investimento e operacionalizações econômicas são feitas em par de igualdade com suas possíveis consequências para a sociedade, ou seja, uma vez que o social e o econômico alcançam mesmo nível de relevância analítica, intenta-se a conquista da legitimação dos lucros organizacionais por meio de ações organizacionais orientadas por premissas de sustentabilidade (ELKINGTON, 1999; SAVITZ; WEBER, 2007; MUNCK; BORIM-DE-SOUZA, 2009; CALLAD0; 2010). A Figura 1 representa esta ideia.

Fundamentando-se em Elkington (1999) e Savitz e Weber (2007), é possível concluir que a integração dos pilares, pelas bases desse estudo convertidos em sustentabilidades, faz emergir intentos organizacionais que representam a integração e os meios de viabilização das três sustentabilidades. Sendo assim, a partir da integração entre os pilares social e econômico verifica-se a inserção social, entendida como o engajar da população (ou organização) em favor do coletivo, de modo que todos possam ter acesso à informação, alimentação, saúde, educação, habitação, trabalho, renda e dignidade. À medida que há interrelação entre os pilares econômico e ambiental, emerge o conceito de ecoeficiência, debatido em maior profundidade no próximo tópico. Já a justiça socioambiental ocorre quando a organização consegue articular o pilar social com o ambiental e passa a tratar da equalização da distribuição dos benefícios e dos constrangimentos impostos pela legislação ambiental, ou mesmo pelos problemas ambientais, entre diferentes grupos sociais (ELKINGTON, 1999; SAVITZ; WEBER, 2007). Como citado anteriormente, a gestão integrada dos três pilares da sustentabilidade organizacional é fator crucial para o alcance do desenvolvimento sustentável nas organizações.

Oliveira (2002) compreende que a consolidação da proposta do TBL, o questionamento e o repensar do gerenciamento de respostas/ações organizacionais passam a visualizar, de certa forma, a função social e ambiental da organização como membro de um sistema integrado à sociedade. Questões concernentes à missão, às estratégias, às crenças e aos valores que serão propagados no longo prazo, serão contempladas neste repensar. Savitz e Weber (2007) ainda argumentam que ao medir o impacto das atividades operacionais das organizações, a estrutura do TBL capta a essência da sustentabilidade organizacional.

Adverte-se que as três sustentabilidades da sustentabilidade organizacional devem ser desenvolvidas de maneira equilibrada, ou ao menos otimizada. Assim, será concedida à organização a possibilidade de atuar em conformidade com os preceitos da ecoeficiência, inserção social e justiça socioambiental, conceitos mais palpáveis, passíveis de mensuração e mais próximos da realidade organizacional.

Postas as explanações acerca da sustentabilidade organizacional, considera-se pertinente elencar os principais conceitos vistos, os quais são essenciais para a continuação da elaboração do quadro teórico deste trabalho. 0 Quadro 2 dispõe tais definições.

Reconhece-se que o TBL constitui uma das poucas abordagens que consegue estar presente nos contextos organizacionais devido à sua complexidade inerente. Além de abordar os três pilares da sustentabilidade, o TBL propõe que sua operacionalização seja simultânea e interativa (ELKINGTON, 1999; NORMAN; MacDONALD (2003); DILLICK; HOCKERTS, 2002; HUPPES; ISHIKAWA, 2005; YOUNG; TILLEY, 2006).

Como será visto adiante, essa proposta interativa do TBL converge diretamente com a proposta deste estudo sobre a sua operacionalização nas organizações por meio da gestão por competências, a qual se adequa de maneira propícia e pertinente por proporcionar

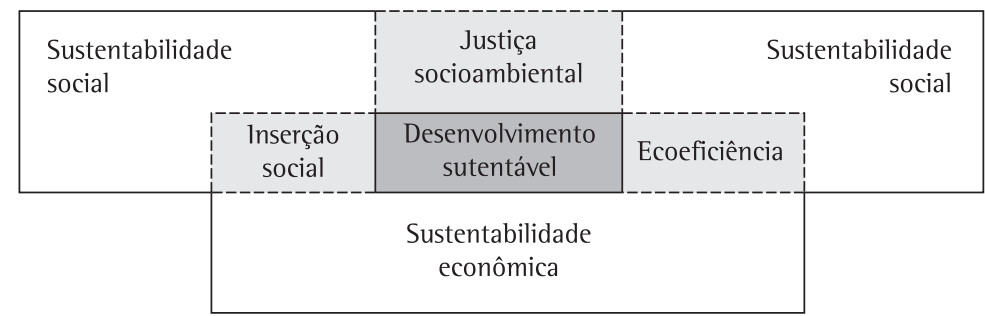

Figura 1. Elementos da sustentabilidade organizacional. Fonte: adaptado de Savitz e Weber (2007). 
Quadro 2. Definição conceitual dos elementos da sustentabilidade organizacional.

\begin{tabular}{|c|c|}
\hline Elemento conceitual & Definição \\
\hline $\begin{array}{l}\text { Sustentabilidade } \\
\text { organizacional }\end{array}$ & $\begin{array}{l}\text { Representa a busca de um equilíbrio entre o que é socialmente desejável, economicamente viável e ambientalmente } \\
\text { sustentável a fim de contribuir para o desenvolvimento sustentável em seu domínio político, de modo a propiciar a } \\
\text { sobrevivência das gerações presente e futuras. }\end{array}$ \\
\hline $\begin{array}{l}\text { Sustentabilidade } \\
\text { organizacional } \\
\text { econômica }\end{array}$ & $\begin{array}{l}\text { Representa a geração de riqueza das organizações pela e para a sociedade, por meio do fornecimento de bens } \\
\text { e serviços. Indica que a organização possui a capacidade de realizar suas atividades de maneira responsável com } \\
\text { lucratividade considerável. }\end{array}$ \\
\hline $\begin{array}{l}\text { Sustentabilidade } \\
\text { organizacional } \\
\text { ambiental }\end{array}$ & $\begin{array}{l}\text { Refere-se à conservação e ao manejo dos recursos naturais, à medida que vai além do cumprimento da lei ou de } \\
\text { iniciativas como reciclagem e uso eficiente de recursos energéticos. }\end{array}$ \\
\hline $\begin{array}{l}\text { Sustentabilidade } \\
\text { organizacional social }\end{array}$ & $\begin{array}{l}\text { Diz respeito ao alcance da igualdade e à participação de todos os grupos sociais na construção e manutenção do } \\
\text { equilíbrio do sistema, compartilhando direitos e responsabilidades, em níveis local, nacional e global. }\end{array}$ \\
\hline Ecoeficiência & $\begin{array}{l}\text { Combinação entre os pilares ambiental e econômico. Ao mesmo tempo em que reduz os impactos ambientais, promove } \\
\text { a utilização racional dos recursos naturais. }\end{array}$ \\
\hline Inserção social & $\begin{array}{l}\text { Resultado da integração entre os pilares social e econômico. Garante, aos indivíduos, recursos suficientes para o seu } \\
\text { acesso a oportunidades e desenvolvimento equitativo frente aos objetivos organizacionais. }\end{array}$ \\
\hline Justiça socioambiental & $\begin{array}{l}\text { Resultado da integração entre os pilares social e ambiental. Assegura aos indivíduos o recebimento equilibrado e } \\
\text { contextual dos malefícios e benefícios sociais e ambientais advindos das atividades organizacionais. }\end{array}$ \\
\hline
\end{tabular}

Fonte: elaborado pelos autores.

uma ambiência facilitadora de discussões sobre as problemáticas da organização nas quais a temática da sustentabilidade se insere. Sendo assim, no próximo tópico serão abordadas breves considerações sobre competências organizacionais no que tange à sua importância e características principais.

Vistas as considerações basilares sobre a sustentabilidade organizacional, faz-se necessária uma abordagem acerca de premissas da ecoeficiência, pivô teórico do presente artigo, para a elaboração do framework.

\section{Premissas da ecoeficiência}

Independentemente do que venha motivar a gestão sustentável, ela parece ser uma tendência imprescindivel às organizações. Bleischwitz (2003) discute a necessidade de um modelo de gestão que leve em conta não somente fatores financeiros mas também fatores que a disciplina econômica denomina como externalidades positivas e negativas, no caso, fatores relacionados ao meio ambiente. Nesse contexto, a literatura acadêmica investiga o relacionamento entre desempenho organizacional ambiental e financeiro, bases da ecoeficiência.

A despeito de ser bem delineado, Huppes e Ishikawa (2005) afirmam que o assunto "ecoeficiência" mostra-se muito diverso, ou rico de atribuições, quando visto pelo lado positivo. Para os autores, a ecoeficiência resume-se a um instrumento para a revisão da sustentabilidade, à medida que indica uma relação empírica nas atividades econômicas entre custo/valor ambiental e impacto ecológico. De maneira mais ampla, o World Business Council for Sustainable Development - WBCSD (WORLD..., 2000) menciona que a ecoeficiência é alcançada por meio do fornecimento de bens e/ou serviços a preços competitivos, que satisfaçam a necessidade dos consumidores e, ao mesmo tempo, proporcionem qualidade de vida e redução do impacto ambiental bem como do consumo de recursos.

A ecoeficiência é habitualmente calculada como o valor econômico agregado pela companhia em relação ao seu impacto ambiental. Afirma-se então que a ecoeficiência é atingida pela entrega de produtos a preços competitivos e de serviços que satisfaçam as necessidades humanas e promovam a qualidade de vida, enquanto progressivamente reduz os impactos ecológicos (DYLLICK; HOCKERTS, 2002). Nesse mesmo segmento, Piotto (2003) discorre sobre a ecoeficiência como o saber combinar desempenho econômico e ambiental, reduzindo ao mesmo tempo os impactos ambientais; utilizando mais racionalmente matérias-primas e energia; reduzindo riscos de acidentes e melhorando a relação da organização com as partes interessadas (stakeholders).

Por acreditar que ambas as definições supracitadas, entre as pesquisadas, representam um nível maior de abrangência, ou seja, envolvem não somente aspectos quantitativos concernentes ao desempenho financeiro, mas também aspectos qualitativos que abordam os relacionamentos da organização e que, ainda, aproximam-se do conceito de competências abordado posteriormente, adotou-se como definição de ecoeficiência no presente artigo o seguinte: a ecoeficiência organizacional é o saber combinar desempenho econômico e ambiental, por meio da entrega de produtos a preços competitivos e de serviços que satisfaçam as necessidades humanas e promovam a qualidade de vida, utilizando-se de forma progressivamente mais racional de matérias-primas e energia; reduzindo os riscos de impactos ecológicos 
e melhorando a relação da organização com as partes interessadas (DYLLICK; HOCKERTS, 2002; PIOTT0, 2003).

Segundo Salgado (2004), a inserção de práticas ecoeficientes direciona a organização para uma grande vantagem competitiva diante de seus concorrentes, e para que isso ocorra existem três preceitos fundamentais que devem ser aplicados: (1) redução do consumo de recursos naturais, tais como energia, matérias, água e solo; (2) redução no impacto na natureza, a qual se entende pela diminuição na poluição do ar e da água; e (3) aumento da produtividade ou no valor do produto/serviço.

Sisinno e Moreira (2005) ainda defendem que várias são as vantagens ocasionadas pela implantação da ecoeficiência, tanto tangíveis como intangiveis: minimização dos danos ambientais, o que reduz os riscos e as responsabilidades derivadas; promoção de condições ótimas de segurança e saúde ocupacional; melhoria da eficiência e competitividade, que impulsionam a inovação; melhoria da reputação e do relacionamento com os órgãos ambientais e com a comunidade; entre outras. Salgado (2004) lembra que a partir do momento em que os executivos reconhecem que a implementação de práticas ecoeficientes não só reduz os impactos ambientais mas também agrega valor ao processo produtivo elas passam a ser mais adotadas nas organizações.

0 enfoque do presente trabalho na competência foco ecoeficiência deve-se ao fato de a necessidade desta surgir para atender simultaneamente ao consumo em ascensão de uma população cada vez mais global e para alcançar uma qualidade ambiental justa (HUPPES; ISHIKAWA, 2005). Além disso, Lorenzetti, Cruz e Riciolli (2008) argumentam que dada a importância reconhecida nos temas ambientais por governos e organizações em todo o mundo, são as medidas ecoeficientes as que participam de maior consenso e aplicação.

Sendo assim, em contexto organizacional, a ecoeficiência depende de um mecanismo de gestão que concede a ela a capacidade de ser avaliada, mensurada e, principalmente, aprimorada (KAPTEIN; WEMPE, 2002). Dentre as alternativas de ferramentas gerenciais valorizadas pela administração contemporânea, destacam-se as competências organizacionais, abordadas com maior profundidade na próxima seção.

\section{Competências organizacionais}

Fleury e Fleury (2008) argumentam que, quando relacionado com o ambiente de trabalho, o conceito de competência assume facetas tanto individuais como coletivas e até mesmo organizacionais. Bitencourt
(2005) defende que as competências, quando analisadas sobre o prisma individual, dizem respeito à formação e ao desenvolvimento das pessoas, e quando estudadas sobre o organizacional referem-se aos aspectos conceituais da organização: estratégia, negócio e competitividade. Fleury e Fleury (2008, p. 30) definem de modo completo e abrangente a competência individual como

[...] um saber agir responsável e reconhecido, que implica mobilizar, integrar, transferir conhecimentos, recursos, habilidades que agreguem valor econômico à organização e valor social aos indivíduos.

Conforme ressalta Dutra (2001), há na literatura conceitos de competência abordados como sendo a entrega e as características da pessoa que podem ajudá-la a entregar com maior facilidade. A definição das competências a partir do detalhamento dos comportamentos de entrega é mencionada por Woodruffe (1991), o qual afirma que o processo de definição de competências deve, em primeiro lugar, determinar um conjunto de comportamentos de entrega. Dutra (2001) inclui como dimensão da competência a noção de entrega, que se refere àquilo que a pessoa pode e quer entregar à organização. Munck et al. (2011) concordam com o autor sobre o fato de que uma pessoa deter um conjunto de conhecimentos, habilidades e atitudes, não implica necessariamente que a organização se beneficie diretamente deles; a verificação da "entrega" indicaria este benefício.

Nesse contexto, Fischer (2002) salienta que um modelo de gestão de pessoas pode ser definido como a maneira pela qual uma organização se estabelece para gerenciar e orientar o comportamento humano no ambiente de trabalho. No caso de modelos de competências, uma das formas mais usadas para a descrição do resultado esperado é por meio da especificação dos comportamentos que representam entrega (MOURA; SOARES, 2010).

Markus, Cooper-Thomas e Allpress (2005) sustentam que para a adoção dos conceitos de competências, a organização deve incorporar modelos de competências, os quais contenham os princípios determinados pelo departamento de recursos humanos. Cada modelo deve ser tão específico quanto seu conteúdo, desde que aponte suas definições, características, conceitos e indicadores de mensuração. Assim, os modelos de competência destacam-se pela sua diversa aplicabilidade e abrangência em várias situações.

De acordo com Borim-de-Souza (2010), ao tratar-se das competências das organizações, ou das competências organizacionais, não se menciona a ideia de ter a organização como competente por si 
mesma, mas se concebe a organização competente em determinados aspectos, justamente pela decorrente competência de gerir suas redes de relacionamento e de desenvolver as competências dos indivíduos nelas inseridos.

Mills et al. (2002) consideram as competências organizacionais como uma maneira para descrever quão bem, ou não, a organização tem potencial para o desempenho adequado em suas atividades centrais e, assim, elas podem orientar a melhoria de suas atividades, a avaliação dos recursos disponíveis e sua utilização e a ativação de novos recursos, ante o contexto competitivo. Os autores acreditam que a competência organizacional é mais bem vista como uma variável antes que um atributo, ou seja, não é algo que a organização possui ou não, mas algo que ela tem em certo nível em relação aos concorrentes. Complementarmente, Maggi (2006) frisa que a competência organizacional é definida como um saber fazer coletivo de alta qualidade.

Dessas considerações iniciais há que se ressaltar que a noção de entrega é utilizada comumente para avaliação individual e não organizacional, como é a intenção desse artigo. No entanto, acredita-se que a avaliação do desempenho da organização realizada a partir da noção de entrega consiste em um modo possível e pertinente de avaliar competências organizacionais. A justificativa para tal afirmação reside no entendimento, já referencialmente explorado, de que são as entregas dos comportamentos esperados (seja do indivíduo ou da organização), a partir de determinados padrões, que traduzem seu desempenho estratégico (MUNCK et al., 2011).

0 nível de competência apresentado pela atividade organizacional depende de seis fatores determinantes: a riqueza dos recursos disponíveis; a apropriação dos recursos para a atividade referida; o modo como os recursos são articulados e gerenciados; a frequência do exercício da atividade; o desempenho de competências de suporte; e a prioridade dada à atividade, principalmente quando os recursos utilizados são compartilhados (MILLS et al., 2002). Entretanto, antes de definir quais são os níveis de competências de uma organização, é primordial saber como tratá-las, gerenciá-las, desenvolvê-las e como obter valor a partir delas. São cinco as categorias de competências organizacionais definidas por Mills et al. (2002), elencadas no Quadro 3:

Nota-se que as cinco categorias mencionadas são todas dependentes da existência de recursos diversos, tangíveis ou intangíveis, que deverão ser articulados. Mills et al. (2002) advogam que existem três meios básicos para que uma competência se torne importante: o primeiro, a exigência de a competência ser sustentada por um ou mais recursos importantes, de maneira efetiva, comparada a seus concorrentes; em seguida, deve ser viável para a corporação coordenar e articular um vasto número de recursos individuais em uma competência; e, por fim, em vez de um único recurso ser raro e valioso, a união e combinação desses possibilitará a formação de uma competência rara e valiosa.

Vale lembrar que as competências organizacionais advêm das individuais, portanto é válido tratar aspectos da gestão de pessoas segundo o conceito de competências. Dutra (2001, p. 25), reforça a constatação ao afirmar:

[...] são as pessoas que, ao colocarem em prática o patrimônio de conhecimentos da organização, concretizam as competências organizacionais e fazem sua adequação ao contexto [...].

Brandão e Guimarães (2001) defendem que a gestão de competências faz parte de um sistema maior de gestão organizacional. Trata-se de um processo contínuo que tem como ponto inicial a estratégia da organização e que direciona suas ações para captação e desenvolvimento das competências necessárias ao cumprimento de seus objetivos (MUNCK; MUNCK; BORIM-DE-SOUZA, 2011).

Ao refletir sobre as definições concedidas pelos autores estudados, chegou-se à constatação de que a definição de competências organizacionais que melhor se adequa ao contexto desse estudo provém das contribuições de Fleury e Fleury (2008), Dutra (2001), Mills et al. (2002) e Maggi (2006). Dessa forma, a competência organizacional é entendida

Quadro 3. Categorias de competências organizacionais.

\begin{tabular}{cl}
\hline Categoria & \multicolumn{1}{c}{ Descrição } \\
\hline Competência foco (core competence) & $\begin{array}{l}\text { Refere-se às atividades mais importantes para a organização, as quais são essenciais para sua } \\
\text { sobrevivência e centrais para sua estratégia. } \\
\text { Competência distintiva }\end{array}$ \\
$\begin{array}{l}\text { São atividades importantes da organização, reconhecidas pelos clientes como diferenciais e } \\
\text { que assim promovem vantagem competitiva. }\end{array}$ \\
Um número menor de atividades desenvolvidas por uma unidade de negócio da firma. \\
Competência da unidade de negócio & $\begin{array}{l}\text { Uma atividade que é valorizada por fomentar uma série de outras atividades. } \\
\text { Capacidade dinâmica }\end{array}$ \\
\hline
\end{tabular}

Fonte: adaptado de Mills et al. (2002). 
como um saber fazer e saber agir coletivo responsável e reconhecido que implica mobilizar, integrar, transferir conhecimentos, recursos e habilidades que agreguem valor econômico à organização e valor social aos indivíduos. Ademais, a avaliação das entregas definidas para as competências organizacionais descreve quão bem, ou não, o desempenho da organização em as suas atividades centrais é adequado.

Percebe-se, assim, que esse conceito adotado converge com o que já foi concebido como a definição de ecoeficiência organizacional, exposto no tópico anterior, ou seja, a ecoeficiência organizacional é o saber combinar desempenho econômico e ambiental por meio da entrega de produtos a preços competitivos e de serviços que satisfaçam as necessidades humanas e promovam a qualidade de vida, enquanto utilizando-se de forma progressivamente mais racional de matérias-primas e energia; reduzindo os riscos de impactos ecológicos e melhorando a relação da organização com as partes interessadas (DYLLICK; HOCKERTS, 2002; PIOTTO, 2003).

Posto isso, faz-se necessária uma referência no que tange à conexão entre competências organizacionais, sustentabilidade organizacional e ecoeficiência.

\section{A relação entre competências, sustentabilidade organizacional e ecoeficiência}

Em um ambiente envolvido por ações estratégicas, as competências representam os conceitos que explicam o teor competitivo das organizações. As competências foco agregam um valor diferenciado para os clientes das organizações e são articuladas por evoluções exigidas pelas ações estratégicas das organizações, em conformidade com o produto e o mercado em que elas atuam (MILLS et al., 2002; FLEURY; FLEURY, 2008).
Identificação qual é sua vantagem competitiva leva a organização a posicionar-se comparativamente ante os concorrentes. A vantagem competitiva sustentável de uma organização origina-se, então, do conjunto de habilidades, experiências, capacidade de inovação, conhecimentos, compreensão do mercado, informações disponíveis e acessíveis que combinados inteligentemente comporão as competências organizacionais (MUNCK, 2005).

Assim, a descrição das competências foco de uma organização e a sua estruturação por um modelo pode ser um ponto inicial para o desenvolvimento dos planejamentos estratégicos, os quais alinharão necessidades organizacionais, preocupações mercadológicas e perspectivas pessoais (MILLS et al., 2002; FLEURY; FLEURY, 2008).

Borim-de-Souza (2010) propõe o alinhamento entre os conceitos de competências e desenvolvimento sustentável e afirma que enquanto a competência oferece a capacidade de gerir a sustentabilidade organizacional e o desenvolvimento sustentável, o alinhamento conecta os conhecimentos organizacionais sobre competências às preocupações econômicas, sociais e ambientais vivenciadas pelas organizações por meio de processos que concedam cada vez mais força a este relacionamento.

0 objetivo é que tal relacionamento possa, em um primeiro momento, conquistar a competência organizacional da sustentabilidade organizacional e em um segundo momento, a metacompetência do desenvolvimento sustentável (influenciada pelo acontecimento e a expressão das competências distintivas e competências foco). Esse raciocínio é expresso por meio da Figura 2.

Pelo raciocínio exposto, é necessário então para a organização primeiramente desenvolver a ecoeficiência, a justiça ambiental e a inserção social como competências foco, as quais desembocam na formação de competências distintivas "sustentabilidade

\begin{tabular}{|c|c|c|}
\hline A organização com melhores condições de desenvolver-se sustentavelmente, e com agente ativo na busca de um & Metacompetência \\
desenvolvimento sustentável & $\begin{array}{c}\text { Competência } \\
\text { organizacional }\end{array}$ \\
\hline \begin{tabular}{|c|c|c|} 
Sustentabilidade \\
econômica
\end{tabular} & $\begin{array}{c}\text { Sustentabilidade } \\
\text { social }\end{array}$ & $\begin{array}{c}\text { Competências } \\
\text { distintivas }\end{array}$ \\
\hline Eco-eficiência & $\begin{array}{c}\text { Sustentabilidade } \\
\text { ambiental }\end{array}$ & Competências \\
foco
\end{tabular}

Figura 2. 0 alinhamento entre sustentabilidade e competências em contexto organizacional. Fonte: adaptado de Borim-de-Souza (2010, p. 115). 
organizacional econômica", "sustentabilidade organizacional ambiental" e "sustentabilidade organizacional social". Segundo o autor, se plenamente desenvolvidas, tais competências distintivas permitem o alcance da competência organizacional da sustentabilidade organizacional. Em sua essência, as três sustentabilidades das organizações são classificadas como distintivas, pois são atividades primordiais da organização, reconhecidas pelos clientes como diferenciais e assim promovem vantagem competitiva. 0 autor afirma ainda que a competência da sustentabilidade organizacional também é uma capacidade dinâmica, haja vista a organização depender de sua capacidade de adaptar e renovar suas competências ao longo do tempo. Desse modo, o desenvolvimento sustentável é compreendido como uma metacompetência consequente, também, da competência organizacional de alcançar a sustentabilidade organizacional (BORIM-DE-SOUZA, 2010).

A gestão por competências pode ser compreendida como uma resposta aos anseios sociais por ações organizacionais voltadas para a sustentabilidade. Ao interligar e aproximar indivíduos e organizações, a gestão por competências propicia uma ambiência facilitadora de discussões sobre as problemáticas da organização, tanto as relacionadas aos assuntos econômicos, quanto as relacionadas aos assuntos socioambientais.

Esta definição aproxima-se do que já foi dito sobre a gestão de competências organizacionais. Viu-se que a gestão eficiente de competências, por meio da avaliação de entregas, permite aprimoramento na elaboração e desenvolvimento de estratégias, que o modelo de gestão de competências implantado deve buscar a evolução do indivíduo em sua perspectiva profissional e pessoal, para que tais ações reflitam-se coletivamente e como consequência explorem e aperfeiçoem o teor competitivo da organização.

Viu-se também que dentre os fatores determinantes do nível de competência apresentado pela atividade organizacional está o desempenho de competências de suporte, sendo assim, avaliar a ecoeficiência, a inserção social e a justiça ambiental como competências foco da sustentabilidade organizacional e, por conseguinte, suas competências de suporte, é fundamental.

A partir das contribuições de Elkington (1999), com a estrutura do TBL, de Savitz e Weber (2007), com a fusão das três sustentabilidades da sustentabilidade organizacional (social, econômica e ambiental), e de Mills et al. (2002) com as categorias de competência organizacional, foi considerado que a competência organizacional "capacidade de desenvolver-se sustentavelmente" é composta por três competências foco também organizacionais, já citadas no tópico anterior: inserção social, justiça socioambiental e ecoeficiência. Vale lembrar que tais competências resultam de integrações específicas realizadas entre as três sustentabilidades (social, econômica e ambiental), competências distintivas da sustentabilidade organizacional.

Com base nas diretrizes do WBCSD (WORLD..., 2000), ao se considerar a estreita relação entre sustentabilidade ambiental e sustentabilidade econômica é possível destacar sete dimensões da ecoeficiência aplicáveis para toda organização que forneça produtos e serviços, modifique processos ou pratique qualquer outra ação que tenha correlação com o meio ambiente. São as seguintes: (a) reduzir a intensidade do consumo de materiais em produtos e serviços; (b) reduzir a intensidade do consumo de água e energia em produtos e serviços; (c) reduzir a dispersão de compostos tóxicos; (d) promover a reciclagem; (e) maximizar o uso de recursos renováveis; (f) estender a durabilidade dos produtos; e (g) aumentar a intensidade do uso de produtos e serviços.

Dessa forma, ao assumir que os produtos e serviços fornecidos devem permitir o desenvolvimento econômico, eles serão mais eficientes do ponto de vista ambiental à medida que utilizem as sete dimensões da ecoeficiência supracitadas e sejam mais efetivos na sua utilização individualmente (WORLD..., 2000). Esses elementos ainda mostram de maneira clara que a ecoeficiência não se limita a mudanças incrementais no uso de recursos. Ao incluir elementos como durabilidade do produto ou intensidade de serviços, o conceito acaba por incluir a redefinição do produto feito ou mesmo a forma de conduzir os negócios. Cabe destacar que tais dimensões devem ocorrer simultaneamente para que a ecoeficiência seja alcançada pela organização.

Para as finalidades deste trabalho, entende-se que essas sete dimensões da ecoeficiência são competências de suporte a serem desenvolvidas necessariamente pela organização, a fim de que seja alcançada a ecoeficiência. Admite-se aqui que tais dimensões são competências de suporte a competência foco da ecoeficiência organizacional, por sua característica intrínseca de fomentar o desenvolvimento de outras atividades da organização. A partir dessa classificação, foi elaborado o Quadro 4, que expõe e descreve o objetivo de cada uma das competências de suporte para o alcance da ecoeficiência.

A otimização do consumo de materiais em produtos e serviço e do uso de água e de energia têm por finalidade, essencialmente, a redução do consumo de materiais na atividade produtiva. Por esta redução entende-se que os processos de trabalho serão concomitantemente afetados e será necessário o aprofundamento no conhecimento sobre os mesmos, 
Quadro 4. Competências potencializadoras da ecoeficiência.

\begin{tabular}{|c|c|}
\hline Competência de suporte & Objetivo \\
\hline Otimização do consumo de materiais em produtos e serviços & Reduzir a intensidade do consumo de materiais em produtos e serviços \\
\hline Otimização do uso de água e de energia em produtos e serviços & $\begin{array}{l}\text { Reduzir a intensidade do consumo de água e energia em produtos e } \\
\text { serviços }\end{array}$ \\
\hline Minimização da dispersão de compostos tóxicos & Reduzir a dispersão de compostos tóxicos \\
\hline Promoção da reciclagem & Promover a reciclagem no ambiente interno e externo da organização \\
\hline Maximização do uso de recursos renováveis & Maximizar o uso de recursos renováveis \\
\hline Extensão da durabilidade dos produtos & Estender a durabilidade dos produtos \\
\hline Aumento da intensidade do uso de produtos e serviços & Aumentar a intensidade do uso de produtos e serviços \\
\hline
\end{tabular}

Fonte: elaborado a partir das finalidades do trabalho.

haja vista a alteração no consumo de inputs e os outputs. Assim, tem-se justificada categorização em competência de suporte. A partir da diminuição dos impactos ambientais por meio da redução da entrada de materiais (recursos naturais, água, ar e energia) por unidade de produção, ou seja, a otimização, nota-se a possibilidade de redução de custos e de ganho produtivo com a utilização de menores quantidades de recursos naturais (WORLD..., 2000).

A minimização da dispersão de compostos tóxicos e a maximização do uso de recursos renováveis possuem como principal objetivo a revalorização de subprodutos e resíduos, com vistas ao desperdício zero. Tais competências são consideradas de suporte, já que se referem a um trabalho e a um objetivo específico, em que devem ser aplicados conhecimentos minuciosos para sua efetivação, e que assim possibilitam a realização ou não realização de outras atividades produtivas, como manutenções exaustivas e gerenciamento de resíduos.

Já o aumento da intensidade do uso de produtos e serviços (aumento da funcionalidade) e a extensão da durabilidade dos produtos (aumento no ciclo de vida do produto), além de fomentarem atividades internas à organização, podem afetar o comportamento do consumidor final, por meio de sua percepção. Tal caracterização é baseada na argumentação de Savitz e Weber (2003): ao oferecer produtos melhores, ambientalmente aceitáveis, com melhor funcionalidade, a organização atinge maior rentabilidade e participação de mercado. Logo, maior vantagem competitiva the é auferida.

Por fim, a promoção da reciclagem é classificada como uma competência de suporte, principalmente ao se tratar da reciclagem interna (dentro da organização, orientada para a produção), porém não se desconsidera sua importância quando se trata da reciclagem externa (promoção de reciclagem direcionada a consumidores, por exemplo, embalagens retornáveis). A reciclagem, de acordo com Forlin e Faria (2002), pode ser entendida como a implementação de processos e técnicas para otimizar a utilização de energia, matérias-primas, produtos e materiais empregados na fabricação de produtos (bens ou serviços). Pelo próprio conceito de reciclagem, percebe-se a fundamentada necessidade de alteração nos fluxos produtivos, em outras palavras, do desenvolvimento da competência de suporte dentro da organização.

Foi exposto anteriormente que a avaliação das entregas definidas para as competências organizacionais descreve quão bem, ou não, o desempenho da organização suas atividades centrais é adequado. No caso das competências de suporte da competência foco da ecoeficiência, esse quadro não difere. Dessa forma, cada objetivo das competências de suporte da ecoeficiência deve gozar de parâmetros pré-estabelecidos, padrões esses conferidos pelo contexto em que a organização está inserida. Isso significa que a redução, intensificação ou maximização de quaisquer atividades que promovam/desenvolvam as competências de suporte da ecoeficiência podem variar de acordo com a realidade atual de cada organização. Essa constatação será também uma das bases em que se fundamentará o framework representativo do acontecimento da ecoeficiência organizacional. Vistas então as competências da ecoeficiência, a próxima seção irá apresentar a construção de ferramenta de análise que aponte os níveis de ecoeficiência que se pode encontrar numa organização.

\section{A construção do framework representativo das competências potencializadoras da ecoeficiência organizacional}

Na visão de Siena (2008), materializar o conceito desenvolvimento sustentável e, por conseguinte, a sustentabilidade organizacional, é um problema complexo, haja vista as bases conceituais sobre as questões envolvidas não estarem consolidadas. Contudo, independentemente do emaranhado de visões sobre o tema, é fato que a sustentabilidade está presente como questão fundamental na política dos governos. Por essa razão, é cada vez mais importante a identificação de conjuntos de indicadores que permitam avaliá-la. 
Como já apresentado, a ecoeficiência consiste em uma competência de suporte à sustentabilidade organizacional, logo, a utilização de instrumentos capazes de mensurá-la torna-se imperativa. Salgado (2004) lembra que como a ecoeficiência relaciona-se com a estratégia competitiva e o desenvolvimento sustentável da organização, o conceito de ecoeficiência em si já prevê a definição de indicadores capazes de medir o desenvolvimento de um empreendimento.

Atualmente, muitas organizações adotaram programas e projetos a fim de padronizar relatórios ambientais e medidas de ecoeficiência, alguns aplicáveis a uma grande variedade de organizações, outros específicos para determinados setores. No entanto, Jung, Kim e Rhee (2001) ressaltam que os tipos de mensuração de desempenho ambiental existentes descritos na maioria dos estudos demonstram confusão e arbitrariedade conceitual de desempenho ambiental. Verifica-se que inconsistências metodológicas em avaliações e medições podem inibir pesquisas na área e dificultar comparações diretas entre organizações do mesmo setor. Siena $(2008$, p. 359) contribui para tal constatação e ainda afirma que "[...] não há consenso sobre o que medir, como medir e, principalmente, sobre como ponderar e combinar dados [...]".

No que tange às considerações feitas até então, é possível observar que vários estudos argumentam a favor de tais instrumentos de mensuração, porém alertam sobre a falta de consenso sobre eles, o que se torna um fator limitante de avanços em pesquisas científicas e também em comparações metodológicas ou de resultados. Ainda assim, os trabalhos existentes geralmente tratam da sustentabilidade, ou do desenvolvimento sustentável, e não da ecoeficiência, e estudos da sua relação com a gestão de competências ainda não foram encontrados, conforme mencionado na introdução. Por essa razão, percebe-se que a ferramenta de análise bem como o framework a serem desenvolvidos neste artigo devem ser instrumentos viáveis e consistentes para a avaliação do potencial de a organização ser ecoeficiente, a partir do nível de entrega de suas competências de suporte. Fala-se em potencial, em virtude de que o fato de uma organização possuir e utilizar um conjunto de recursos e atributos que propiciem uma melhor entrega de suas competências e, assim, atingir um melhor desempenho não indica que a organização detenha tal desempenho, e que desse decorra realmente vantagem competitiva em relação aos seus concorrentes.

Uma vez que a ferramenta de análise proposta será parte fundamental do framework representativo das competências de suporte da ecoeficiência, cabe, em primeiro lugar apresentar sua elaboração. Siena (2008), ao propor uma escala de mensuração do desenvolvimento sustentável, utilizou o sistema de bandas. Pelos estudos do autor e adaptações realizadas para as finalidades deste trabalho, à ferramenta de análise proposta foi concedido o tratamento de "taxionomia CE7", sigla devida às "sete competências da ecoeficiência", tema de principal discussão neste artigo.

A construção dessa taxionomia foi fundamentada a partir de um quadro de verificação composto por uma escala likert de seis pontos, de acordo com o nível de entrega da organização sobre o cumprimento de cada competência de suporte da ecoeficiência. A escala Likert responde à seguinte configuração: base 0 (zero) e extremo 100 (cem); 0 é base da ausência de entrega; 20 refere-se à entrega insuficiente; 40 indica entrega fraca; 60 faz menção à entrega regular; 80 significa a entrega suficiente; e, por fim, 100 reflete a entrega máxima da organização em busca de atingir o objetivo proposto e, assim, desenvolver a respectiva competência. 0 Quadro 5 a seguir apresenta esse raciocínio.

0 referido quadro de verificação para fins de operacionalização deste estudo, e como sugestão inicial, deverá ser preenchido pelos gestores responsáveis pelas áreas de sustentabilidade e gestão de pessoas da organização em estudo. Em segundo momento, recomenda-se também o preenchimento desse quadro de verificação por membros da organização localizados em patamares inferiores da hierarquia organizacional, a fim de promover a comparação entre percepções de líderes e liderados. A cada competência de suporte da ecoeficiência deverá ser atribuído somente um nível de entrega.

Uma das análises possíveis a partir do quadro de verificação é a constatação de respostas por respondente. Nesse caso, a pontuação máxima permitida pelo quadro de verificação é 700, ou seja, se existem sete competências de suporte em que são avaliadas as entregas, e a entrega máxima para cada competência de suporte é indicada com 100 pontos, tem-se que se todas as competências de suporte forem indicadas com 100 pontos cada a somatória dessa pontuação será de no máximo 700 pontos. Sobre essa pontuação deve ser aplicada a representatividade, em percentuais, sem cálculos de ponderação, do nível de entrega geral da organização com as competências de suporte da ecoeficiência propostas. Fala-se em entrega geral devido às proposições teóricas já apresentadas de que para que seja ecoeficiente, a organização deve desenvolver todas as competências de suporte indicadas, de modo integrado e simultâneo (WORLD..., 2000; MILLS et al., 2002). A base da ausência de entrega não foi considerada, pois sua pontuação total será sempre zero, o que indica o potencial nulo da organização para ser ecoeficiente, em qualquer situação. 
Quadro 5. Quadro de verificação de competências de suporte da ecoeficiência.

\begin{tabular}{|c|c|c|c|c|c|c|c|}
\hline $\begin{array}{l}\text { Competência de } \\
\text { suporte }\end{array}$ & Entrega esperada & $\begin{array}{l}\text { Ausência de } \\
\text { entrega (0) }\end{array}$ & $\begin{array}{l}\text { Entrega } \\
\text { insuficiente } \\
\text { (até } 20 \% \text { do } \\
\text { esperado) } \\
20 \text { pontos }\end{array}$ & $\begin{array}{c}\text { Entrega } \\
\text { fraca (entre } \\
21 \% \text { e } 40 \% \\
\text { do esperado) } \\
40 \text { pontos }\end{array}$ & $\begin{array}{c}\text { Entrega } \\
\text { regular } \\
\text { (entre } 41 \% \\
\text { e } 60 \% \text { do } \\
\text { esperado) } 60 \\
\text { pontos }\end{array}$ & $\begin{array}{c}\text { Entrega } \\
\text { suficiente } \\
\text { (entre } 61 \% \\
\text { e } 80 \% \text { do } \\
\text { esperado) } \\
80 \text { pontos }\end{array}$ & $\begin{array}{c}\text { Entrega } \\
\text { máxima (entre } \\
81 \% \text { e } 100 \% \\
\text { do esperado) } \\
100 \text { pontos }\end{array}$ \\
\hline $\begin{array}{l}\text { Otimização do } \\
\text { consumo de } \\
\text { materiais em } \\
\text { produtos e serviços }\end{array}$ & $\begin{array}{l}\text { Redução da } \\
\text { intensidade do } \\
\text { consumo de } \\
\text { materiais em } \\
\text { produtos e serviços } \\
\text { a partir de padrões } \\
\text { pré-estabelecidos }\end{array}$ & & & & & & \\
\hline $\begin{array}{l}\text { Otimização do } \\
\text { uso de água e } \\
\text { de energia em } \\
\text { produtos e serviços }\end{array}$ & $\begin{array}{l}\text { Redução da } \\
\text { intensidade do } \\
\text { consumo de água } \\
\text { e energia em } \\
\text { produtos e serviços } \\
\text { a partir de padrões } \\
\text { pré-estabelecidos }\end{array}$ & & & & & & \\
\hline $\begin{array}{c}\text { Minimização } \\
\text { da dispersão de } \\
\text { compostos tóxicos }\end{array}$ & $\begin{array}{c}\text { Redução da dispersão } \\
\text { de compostos tóxicos } \\
\text { a partir de padrões } \\
\text { pré-estabelecidos }\end{array}$ & & & & & & \\
\hline $\begin{array}{l}\text { Promoção da } \\
\text { reciclagem }\end{array}$ & $\begin{array}{l}\text { Promover e realizar } \\
\text { a reciclagem no } \\
\text { ambiente interno } \\
\text { e externo da } \\
\text { organização }\end{array}$ & & & & & & \\
\hline $\begin{array}{l}\text { Maximização do } \\
\text { uso de recursos } \\
\text { renováveis }\end{array}$ & $\begin{array}{l}\text { Maximizar o uso de } \\
\text { recursos renováveis } \\
\text { a partir de padrões } \\
\text { pré-estabelecidos }\end{array}$ & & & & & & \\
\hline $\begin{array}{l}\text { Extensão da } \\
\text { durabilidade dos } \\
\text { produtos }\end{array}$ & $\begin{array}{c}\text { Estender a } \\
\text { durabilidade } \\
\text { dos produtos a } \\
\text { partir de padrões } \\
\text { pré-estabelecidos }\end{array}$ & & & & & & \\
\hline $\begin{array}{c}\text { Aumento da } \\
\text { intensidade do } \\
\text { uso de produtos e } \\
\text { serviços }\end{array}$ & $\begin{array}{l}\text { Aumentar a } \\
\text { intensidade do uso de } \\
\text { produtos e serviços } \\
\text { a partir de padrões } \\
\text { pré-estabelecidos }\end{array}$ & & & & & & \\
\hline
\end{tabular}

Fonte: elaborado pelos autores.

Outra possibilidade de análise diz respeito à averiguação dos níveis de entrega de cada uma das sete competências de suporte da ecoeficiência. Nesse caso, a pontuação irá variar conforme o total de respondentes de maneira proporcional, ou seja, quanto maior o número de participantes, maior será o total de pontos permitidos a cada competência de suporte. De forma semelhante à do caso anterior, sobre a pontuação máxima obtida deve ser aplicada a representatividade, em percentuais, sem ponderação, do nivel de entrega geral da organização com as competências de suporte da ecoeficiência propostas.

É necessário esclarecer que essa última modalidade de análise não permite a indicação do potencial com que a organização pode ser ecoeficiente, como no caso da análise por respondente exposto acima. Justifica-se que essa classificação somente pode ser feita se todas as competências de suporte forem avaliadas conjuntamente. Segundo o que já foi exposto, para que a organização seja considerada ecoeficiente, suas competências de suporte devem ser integradas e simultaneamente desenvolvidas, logo, uma avaliação particular delas não torna possível tal classificação. No entanto, essa análise é basilar no que concerne à indicação do potencial que cada uma das competências de suporte tem para contribuir para o alcance da competência foco da ecoeficiência. Por meio dessa análise, ainda, a organização pode examinar quais competências necessitam de maior investimento e desenvolvimento e, a partir daí, tomar decisões estratégicas a respeito.

Como já salientado, o quadro de verificação é uma etapa para a utilização da taxionomia CE7. Conforme o nivel de entrega geral das competências de suporte, encontrado por meio da primeira possibilidade de análise apontada, o potencial de a organização ser 
ecoeficiente será indicado em determinado patamar da taxionomia CE7, conforme ilustra a Figura 3.

Ao se interpretar a taxionomia CE7 é possível visualizar a coerência entre as competências de suporte da ecoeficiência e o nível de desenvolvimento em que elas se encontram na organização, tanto de forma particular quanto de forma geral, o que fornece o potencial de a organização ser ecoeficiente. Por exemplo, se a entrega geral das competências de suporte for de $46 \%$, ou seja, uma entrega regular, o potencial de a organização ser ecoeficiente será do mesmo modo regular. Desse modo, para que a organização seja considerada realmente portadora do potencial máximo para a ecoeficiência, ela deve obter um índice de, no mínimo, 81\% de entrega de suas competências de suporte.

Com a posse de tal informação, ressalta-se que a organização terá um grande instrumento de análise, uma vez que a partir dele poderá obter conclusões a respeito de sua conduta ambiental e econômica e vir a mudar procedimentos e posturas que se mostrarem necessários. É preciso, também, destacar que a taxionomia CE7 deve conferir análises a partir do julgamento de profissionais da área de estudo, sendo assim cabe o alerta para a possibilidade da interferência de subjetividades.

Apresentada a construção da taxionomia CE7 e tendo em vista que este artigo busca elaborar uma estrutura que fomente a apreensão do potencial do acontecimento da ecoeficiência em contexto organizacional, o recurso framework será utilizado na tentativa de criar uma referência para a representação da ecoeficiência organizacional a partir da avaliação de entregas de competências de suporte que a viabilizem.

Há que se ressaltar, antes, as diferenças entre um framework e um modelo. Para Harding e Long (1998), um modelo é uma representação dinâmica da realidade e tem como objetivo esclarecer as relações entre diferentes elementos, indica causalidades e interações efetivas. As características de um modelo fazem parte das características dos frameworks. De acordo com Pinheiro-de-Lima e Lezana (2005), é razoável concluir que um modelo é um tipo particular de framework; no entanto, nem todo framework representa um modelo, e este é o caso do framework que aqui será elaborado.

Importante frisar, ainda sobre os frameworks, a contribuição do trabalho de Jabareen (2009), no qual é enfatizado que esses não são apenas coleções de conceitos, mas construções em que cada conceito tem seu papel, e que apresentam não uma definição causal/analítica, mas possibilitam a facilidade nas interpretações. 0 autor acrescenta que o framework, ao invés de oferecer explicações teóricas, como modelos quantitativos, se preocupa com a compreensão e o entendimento e, não sendo de natureza determinística, não permite a previsão de resultados. Nesse contexto, Hoff (2008) argumenta que o framework pode ser usado para a formulação de hipóteses e para testes em futuros estudos empíricos, com vistas não só ao desenvolvimento de procedimentos metodológicos e analíticos adequados, mas também ao teste da sua coerência prática. A proposição de estudos empíricos que possam contribuir para a validação do framework aqui elaborado é de suma relevância.

Por tais constatações, tem-se que o framework a ser apresentado por este artigo deverá facilitar o entendimento sobre a relação entre competências e ecoeficiência no contexto organizacional, de modo a explicitar o potencial que uma organização tem de ser ecoeficiente, por meio da avaliação do nível de entrega de suas competências de suporte. Ademais, a proposição do framework em questão pauta-se em futuras intervenções empíricas, logo, não é intenção aqui prever resultados. Estudos empíricos deverão ser realizados com vistas a contribuir para a coerência e a consistência do framework, além de fundamentar sua validação prática. Sendo assim, a Figura 4 apresenta o framework representativo do acontecimento da ecoeficiência organizacional via competência.

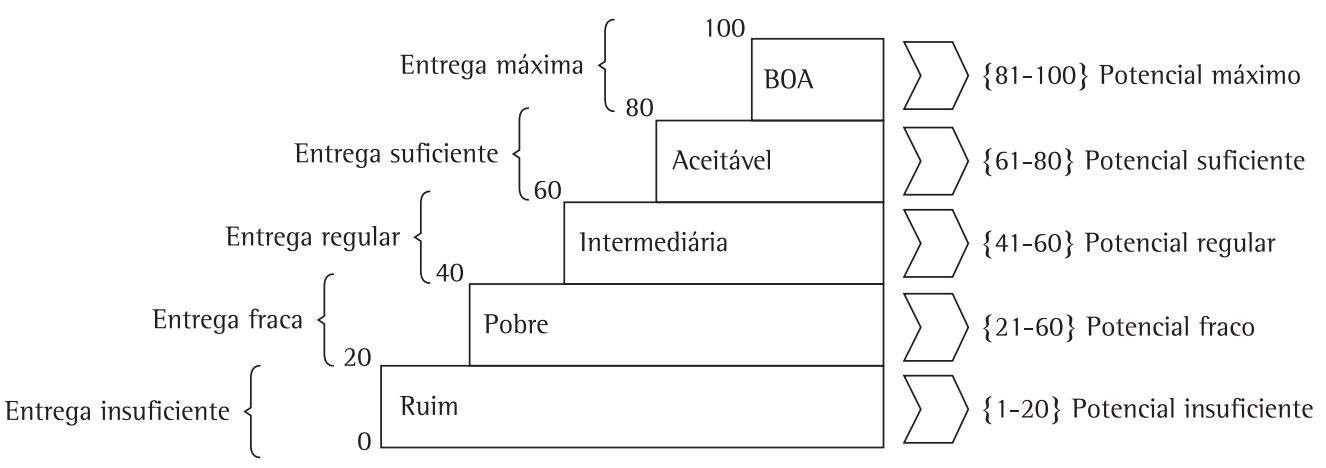

Figura 3. Taxionomia CE7. Fonte: elaborado pelos autores. 


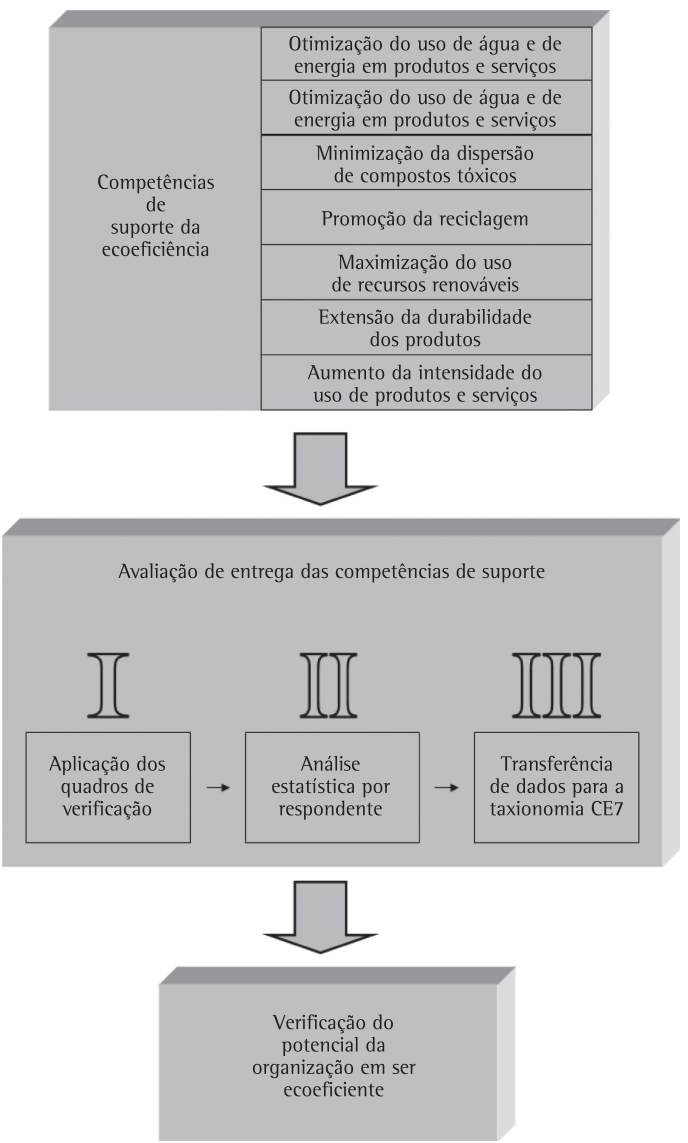

Figura 4. Framework representativo do acontecimento da ecoeficiência organizacional via competência. Fonte: elaborado pelos autores a partir das contribuições de WBCSD (WORLD..., 2000), Dutra (2001), Mills et al. (2002) e Siena (2008).

Observa-se que o framework apresentado responde a toda construção teórica abrangida pelo escopo deste artigo. Inicialmente, traz as sete competências de suporte da ecoeficiência, assim concebidas por meio das sete dimensões da ecoeficiência (WORLD..., 2000) e da categorização de Mills et al. (2002) a respeito das competências organizacionais. 0 constructo seguinte aborda a avaliação de entrega das competências de suporte em questão, fase composta por três etapas: a aplicação de quadros de verificação, a análise estatística por respondente e a transferência de dados para a taxionomia CE7. A avaliação de entregas de competências organizacionais foi desenvolvida a partir dos estudos de Dutra (2001), enquanto o quadro de verificação, a análise estatística e a própria taxionomia CE7 foram elaboradas conforme adaptações baseadas em Siena (2008). Enfim, a verificação do potencial de a organização ser ecoeficiente é realizada pela interpretação da taxionomia CE7 e confere a finalização do framework.
Por este framework é subentendido que as competências de suporte da ecoeficiência já estão presentes na organização, em maior ou menor grau de desenvolvimento. A este entendimento acrescenta-se que ferramentas de criação e gerenciamento das competências de suporte da ecoeficiência ou mesmo a elaboração de "padrões ótimos" em que essas competências devem existir não fazem parte do escopo de investigação deste artigo. Admite-se que instrumentos de gestão e o estabelecimento de parâmetros são imprescindíveis na gestão por competências (DUTRA, 2001; MUNCK, 2005), porém reconhece-se que esses são instrumentos e padrões conferidos pelo contexto em que a organização está inserida. De modo semelhante, as ações e decisões decorrentes após a verificação do potencial de a organização ser ecoeficiente não são aqui pertinentes. Como visto, não é intenção desse framework prever resultados, logo torna-se incabível prever suas implicações estratégicas para a organização.

Observa-se que tais inferências são apoiadas pelo que já se expôs acerca da contribuição da experiência empírica sobre o framework. Sua principal finalidade foi identificada como facilitar o entendimento sobre a relação entre competências e ecoeficiência no contexto organizacional e não indicar causalidades ou propor intervenções a partir de resultados possíveis. Viu-se também que o framework em questão é pautado em futuros estudos empíricos, os quais deverão ser realizados com vistas a contribuir para a coerência e a consistência práticas do framework, além de contribuir para sua validação.

\section{Considerações finais, sugestões de estudos futuros e implicações para a administração}

Este trabalho teve como finalidade propor um framework representativo do acontecimento da ecoeficiência organizacional via competência, ou seja, um framework que por meio da verificação do nível de entrega das competências de suporte da ecoeficiência, indicasse o potencial de a organização ser ecoeficiente.

Após revisão da literatura, chegou-se ao entendimento de que a gestão por competências é uma alternativa concreta para compreender e integrar a rede que permitirá respostas aos anseios sociais por ações organizacionais voltadas para a sustentabilidade. Além disso, expôs-se que a gestão por competência converge diretamente com a operacionalização em meio organizacional da proposta interativa do TBL, a partir da ecoeficiência. 0 presente trabalho teve como prioridade aprofundar os aspectos da ecoeficiência em 
relação à sustentabilidade organizacional, no entanto em momento algum foi pretensão desconsiderar a inserção social ou a justiça socioambiental.

Por essas constatações, o desenvolvimento sustentável é concebido como metacompetência a ser atingida e dentre suas diversas sustentabilidades situa-se a sustentabilidade organizacional. Essa, por sua vez, é sustentada por três outras sustentabilidades, competências distintivas da organização: econômica, social e ambiental. Ao observá-las sob a lente integradora do TBL, desvendam-se três competências foco: a inserção social é atingida por meio da junção das sustentabilidades econômica e social; a justiça socioambiental é obtida a partir da união das sustentabilidades social e ambiental, e a ecoeficiência configura-se a partir da junção entre as sustentabilidades econômica e ambiental. Como base da construção do pensamento, as três competências foco exploradas são primordiais para o alcance do desenvolvimento sustentável.

A partir das proposições teóricas, o passo seguinte foi a construção do framework representativo do acontecimento da ecoeficiência organizacional via competências. Para tanto, foi necessário identificar as sete competências de suporte da ecoeficiência, assim concebidas por meio das sete dimensões da ecoeficiência (WORLD..., 2000) e da categorização de Mills et al. (2002) a respeito das competências organizacionais. Nesse percurso também foi elencada a avaliação de entrega das competências de suporte em questão, a partir dos estudos de Dutra (2001) e de Siena (2008), fase essa composta por três etapas: a aplicação de quadros de verificação, a análise estatística por respondente e a transferência de dados para a taxionomia CE7. Enfim, foi indicada a interpretação da taxionomia CE7, por meio da qual é possível verificar o potencial de a organização ser ecoeficiente.

Observou-se que a aplicação dos quadros de verificação é uma etapa para a utilização da taxionomia CE7. Conforme o nível de entrega geral das competências de suporte, encontrado por meio da análise das respostas por participante da pesquisa, o potencial de a organização ser ecoeficiente será indicado em determinado patamar da taxionomia CE7. Destarte, o nível de entrega em que as competências de suporte podem ser avaliadas irá depender da visão dos respondentes a esse respeito.

0 framework aqui apresentado deverá facilitar o entendimento sobre a relação entre competências e ecoeficiência no contexto organizacional à medida que demonstra o potencial que uma organização tem de ser ecoeficiente, por meio da avaliação do nível de entrega de suas competências de suporte. Ao observar a lógica da competência, percebe-se que a ferramenta proposta poderá sinalizar incoerências nas organizações ditas ecoeficientes na medida em que demonstrarem a não posse das competências necessárias para tal. Ademais, o framework em questão solicita futuras intervenções empíricas, logo, prever resultados não foi intenção, de forma alguma. Estudos empíricos deverão ser realizados com vistas a contribuir para a coerência e a consistência do framework, além de fundamentar sua validação prática.

Faz-se necessária a recomendação da aplicação desta pesquisa como próxima etapa de sua concretização. A realização da aplicação empírica do framework aqui elaborado poderá trazer contribuições importantes à medida que possibilita aos gestores um instrumento de análise de avaliação e orientadora na busca de melhores práticas de ecoeficiência. Além disso, a pesquisa empírica trará contribuições acadêmicas ao vislumbrar novas aplicações, correções e subsídios a este estudo, bem como ao orientar e iniciar novas pesquisas.

De fato, a operacionalização deste estudo também irá perpetuar oportunidades para novos questionamentos relacionados ao tema. Espera-se, com a experiência empirica, integrar conceitos capazes de responder e jogar luz sobre questões em aberto e sobre outras ainda obscuras, tais como: qual o melhor caminho para orientar a formação de competências de suporte da ecoeficiência para desenvolver-se sustentavelmente? Quais das competências são mais requeridas para atender aos anseios do desenvolvimento sustentável? Quais direcionamentos possíveis a organização pode tomar a partir de sua ecoeficiência potencial? Tais considerações não só se justificam como mostram o quanto esses estudos são necessários. Sugere-se também que sejam realizados estudos que aprofundem a relação entre competências e sustentabilidade. Como já dito, as pesquisas na área são escassas, enquanto o campo de estudo apresenta-se vasto. As pesquisas podem ser tomadas em âmbito micro e/ou macro, tratar de competências individuais, coletivas ou mesmo organizacionais, tratar da inserção social, da justiça socioambiental, ecoeficiência ou das três, simultaneamente.

Como conclusão, construir respostas que melhor expliquem as relações propostas, até então consideravelmente ausentes em estudos científicos vinculados à administração, permitirá, no mínimo, estabelecer um debate que crie novos rumos na abordagem das questões em análise.

\section{Referências}

AZAPAGIC, A. Systems approach to corporate sustainability: a general framework. Process Safety and Environmental Protection, v. 81, n. 5, p. 303-316, 2003. http://dx.doi. org/10.1205/095758203770224342 
BITENCOURT, C. C. Gestão de competências e aprendizagem nas organizações. São Leopoldo: Editora Unisinos, 2005.

BLEISCHWITZ, R. Cognitive and institutional perspectives of eco-efficiency. Ecological Economics, n. 46, p. 453-467, 2003. http://dx.doi.org/10.1016/S09218009(03)00186-1

BORIM-DE-SOUZA, R. $O$ alinhamento entre sustentabilidade e competências em contexto organizacional. 2010. 199 f. Dissertação (Mestrado em Administração)-Universidade Estadual de Maringá; Universidade Estadual de Londrina, Londrina, 2010.

BRANDÃO, H. P.; GUIMARÃES, T. A. Gestão de Competências e Gestão de Desempenho: tecnologias distintas ou instrumentos de um mesmo construto? Revista RAE - Revista de Administração de empresas, v. 41, n. 1, p. 8-15, jan./mar. 2001.

CALLADO, A. L. C Modelo de mensuração de sustentabilidade empresarial: uma aplicação em vinícolas localizadas na Serra Gaúcha. 2010. Tese (Doutorado em Agronegócios)-Universidade Federal do Rio Grande do Sul. Porto Alegre, 2010.

DEMO, P. Metodologia do conhecimento científico. São Paulo: Atlas, 2000.

DENZIN, N. K.; LINCOLN, Y. S. Introdução: a disciplina e a prática da pesquisa qualitativa. In: DENZIN, N. K.; LINCOLN, Y. S. O planejamento da pesquisa qualitativa: teorias e abordagens. Porto Alegre: Artmed, 2006. p. 15-42.

DREJER, A. Strategic management and core competencies. Quorumbooks, 2002.

DYLLICK, T.; HOCKERTS, K. Beyond the business case for corporate sustainability. Business Strategy and the Environment, v. 11, p. 130-141, 2002.

DUTRA, J. S. Gestão por competências: um modelo avançado para o gerenciamento de pessoas. São Paulo: Editora Gente, 2001.

DYLLICK, T.; HOCKERTS, K. Beyound the business case for corporate sustentability. Business Strategy and the environment, v. 11, p. 130-141, 2002. http://dx.doi. org/10.1002/bse.323

ELKINGTON, J. Cannibals with forks: the triple bottom line of 21st century business. Oxford: Capstone Publishing Limited, 1999.

FISCHER, A. L. Um resgate conceitual e histórico dos modelos de gestão de pessoas. In: FLEURY, M. T. L. As pessoas na organização. São Paulo: Gente, 2002.

FLEURY, A.; FLEURY, M. T. L. Estratégias empresariais e formação de competências: um quebra-cabeça caleidoscópico da indústria brasileira. 3. ed. São Paulo: Atlas, 2008.

FORLIN, F. J.; FARIA, J. A. Considerações sobre a reciclagem de embalagens plásticas. Polímeros, v. 12, n. 1, p. 1-10, 2002 .

GlL, A. C. Métodos e técnicas de pesquisa social. 6. ed. São Paulo: Atlas, 2008.

GLADWIN, T. N.; KENNELLY, J. J.; KRAUSE, T. S. Shifting paradigms for sustainable development: implications for management theory and research. Academy of Management, v. 20, n. 4, p. 874-907, 1995.

HARDING, S.; LONG, T. Proven management tools. Great Britain: Gower, 1998.
HOFF, D. N. A construção do desenvolvimento sustentável através das relações entre as organizações e seus stakeholders: a proposição de uma estrutura analítica. 2008. Tese (Doutorado em Agronegócios)-Universidade Federal do Rio Grande do Sul, Porto Alegre, 2008.

HUPPES, G.; ISHIKAWA, M. A framework for quantifies eco-efficiency analysis. Journal of Industrial Ecology, v. 9, n. 4, p. 25-41, 2005. http://dx.doi. org/10.1162/108819805775247882

JABAREEN, Y. Building a conceptual framework: philosophy, definitions, and procedure. International Journal of Qualitative Methods, v. 8, n. 4, p. 49-62, 2009.

JAMALl, D. Insights into the triple bottom line integration from a learning organization perspective. Business Process Management Journal, v. 12, n. 6, p. 809-821, 2006. http://dx.doi.org/10.1108/14637150610710945

JUNG, E. J.; KIM, J. S.; RHEE, S. K. The measurement of corporate environmental performance and its application to the analysis of efficiency in oil industry. Journal of Cleaner Production, v. 9, 2001.

KAPTEIN, M.; WEMPE, J. The balanced company: a theory of corporate integrity. 0xford: Oxford University Press, 2002.

KRAJNC, D.; GLAVIC, P. A model for integrated assessment of sustainable development. Resources, Conservation and Recycling, v. 43, n. 2, 2005.

LORENZETTI, D. H.; CRUZ, R. M.; RIClOLl, S. Estratégia empresarial e sustentabilidade: um modelo integrador. Revista da Pós-graduação: Administração, v. 2, n. 3, p. 33-57, 2008.

MAGGl, B. Formação e competências para a mudança organizacional. In: MAGGl, B. Do agir organizacional. São Paulo: Edgard Blücher, 2006. p. 207-239.

MARKUS, L. H.; COOPER-THOMAS, H. D.; ALLPRESS, K. N. Confunded by competencies? An evaluation of the evolution and use of competency models. New Zealand Journal of Pshycology, v. 34, n. 2, p. 117-126, 2005.

MARQUES, J. C. et al. The ecological sustainability trigon - a proposed conceptual framework for creating and testing management scenarios. Marine Pollution Bulletin, v. 58, p. 1773-1779, 2009. http://dx.doi.org/10.1016/j. marpolbul.2009.08.020

MARTINS, G. A.; THEÓPHILO, C. R. Metodologia da investigação científica para ciências sociais aplicadas. São Paulo: Atlas, 2007

McDONOUGH, W.; BRAUNGART, M. Design for the triple bottom line: new tools for sustainable commerce. Corporate Environmental Strategy, v. 9, n. 3, p. 251-258, 2002. http://dx.doi.org/10.1016/S10667938(02)00069-6

MEBRATU, D. Sustainability and sustainable development: historical and conceptual review. Environment Impact Assessment Review, v. 18, p. 493-520, 1998. http:// dx.doi.org/10.1016/S0195-9255(98)00019-5

MILLS, J. et al. Competing though competences. Cambridge: Cambrigdge University Press, 2002.

MORGAN, G.; SMIRCICH, L. The case for qualitative research. Academy of Management Review, v. 5, n. 4, p. 491-500, 1980.

MOURA, M. A.; SOARES, F. E. S. Competências baseadas em comportamentos de entrega e modelo de carreira 
proteano: desafios para as profissionais de secretariado. In: CONGRESSO NACIONAL DE SECRETARIADO, 17., 2010, Fortaleza. Anais... Fortaleza, 2010.

MUNCK, L. Estratégia empresarial, aprendizagem e competências: análise de suas inter-relações em uma empresa de telecomunicações do Norte do Paraná. 2005. Tese (Doutorado em Administração)-Universidade de São Paulo, 2005.

MUNCK, L.; BORIM-DE-SOUZA, R. B. Gestão por competências e sustentabilidade empresarial: em busca de um quadro de análise. Gestão e Sociedade, v. 3, n. 6, p. 254-287, 2009.

MUNCK, L. et al. Modelos de gestão de competências versus processo de validação. Um ponto cego? Revista de Administração, v. 46, n. 2, p. 107-121, 2011.

MUNCK, L.; MUNCK, M. G. M.; BORIM-DE-SOUZA, R Gestão de pessoas por competências: análise de repercussões dez anos pós-implantação. Revista de Administração da Mackenzie - RAM, v. 12, n. 1, p. 4-52, 2011.

NORMAN, W.; MacDONALD, C. Getting to the Bottom of "Triple Bottom Line". Press, Business Ethics Quarterly, 2003. p.1-19.

O'CONNOR, M. The four spheres framework for sustainability. Ecological Complexity, v. 3, p. 285-192, 2006. http:// dx.doi.org/10.1016/j.ecocom.2007.02.002

OLIVEIRA,J.H.R.M.A.I.S.:Método para avaliação deindicadores de sustentabilidade organizacional. 2002. 217 f. Tese (Doutorado em Engenharia de Produção)-Universidade Federal de Santa Catarina, Florianópolis, 2002.

PINHEIRO-DE-LIMA, E.; LEZANA, A. G. R. Desenvolvendo um Framework para Estudar a Ação Organizacional: das Competências ao modelo organizacional. Gestão \& Produção, v. 12, n. 2, p. 177-190, 2005.

PIOTTO, Z. C. Eco-eficiência na Indústria de Celulose e Papel: estudo de caso. 2003. Tese (Doutorado em Engenharia)-Universidade de São Paulo, São Paulo, 2003

RICHARDSON, R. J. Pesquisa social: métodos e técnicas. 3. ed. São Paulo: Atlas, 2008.

SAlGADO, V. G. Proposta de indicadores de ecoeficiência para o transporte de gás natural. 2004. Dissertação (Mestrado em Ciências do Planejamento Energético)-Universidade Federal do Rio de Janeiro.

SAVITZ, A. W.; WEBER, K. A empresa sustentável: o verdadeiro sucesso é lucro com responsabilidade social e ambiental. Rio de Janeiro: Elsevier, 2007.

SHEHABUDDEEN, N.; PROBERT, D.; PHAAL, R. Representing and approaching complex management issues: part 1 - role and definition. Cambridge, 2000. Working Paper UC.

SHWOM, R. Strengthening Sociological Perspectives on Organizations and the Environment. Organization \& Environment, v. 22, n. 3, p. 271-292, 2009. http://dx.doi. org/10.1177/1086026609345216

SIENA, 0. Método para avaliar desenvolvimento sustentável: técnicas para escolha e ponderação de aspectos e dimensões. Revista Produção, v. 18, n. 2, 2008.

SILVA, L. S. A.; QUELHAS, O. L. G. Sustentabilidade empresarial e o impacto no custo de capital próprio das empresas de capital aberto. Gestão \& Produção, v. 13, n. 3, p. 385-395, 2006. http://dx.doi.org/10.1590/ S0104-530X2006000300003

VAN BELLEN, H. M. Indicadores de sustentabilidade - um levantamento dos principais sistemas de avaliação. Cadernos EBAPE.BR, v. 2, n. 1, 2004.

VAN MARREWIJK, M. Concepts and definitions of CSR and corporate sustainability: between agency and communion. Journal of Business Ethics, v. 44, p. 95-105, 2003. http:// dx.doi.org/10.1023/A:1023331212247

WORLD BUSINESS COUNCIL FOR SUSTAINABLE DEVELOPMENT - WBCSD. A eco-eficiência: criar mais valor com menos impacto. Lisboa: WBCSD, 2000.

WOODRUFFE, C. Competent by any other name. Personnel Management, v. 23, n. 9, p. 30-33, Sep. 1991.

YOUNG, W.; TILLEY, F. Can businesses move beyond efficiency? The shift toward effectiveness and equity in the corporate sustainability debate. Business Strategy and the Environment, v. 15, p. 402-415, 2006. http:// dx.doi.org/10.1002/bse.510

\section{Organizational competencies for sustainability: the proposition of a representative framework of the event of eco-efficiency}

\section{Abstract}

The fact that the organizations can structure their competencies in a specific management model is only a starting point for developing a strategic plan linked to aspects of sustainability. Through the elements of eco-efficiency assessors (proposed by the World Business Council for Sustainable Development), which are treated in this article as organizational competencies, this research was developed by an essentially theoretical imprint in order to propose a representative framework of the event of eco-efficiency through organizational competency.

Keywords

Eco-efficiency. Sustainability. Organizational competency. 